\title{
The Relationship Between Students' Research Motivation, Capacity for Independent Work, and Research Outputs: Defining the Good Advisee Using Natural Language Processing
}

\author{
Nitza Davidovitch ${ }^{1} \&$ Eyal Eckhaus ${ }^{2}$ \\ ${ }^{1}$ Head of Academic Quality and Assessment, Head of Teacher Training Program, Ariel University, Israel \\ ${ }^{2}$ Department of Economics and Business Administration, Ariel University, Ariel, Israel \\ Correspondence: Eyal Eckhaus, Department of Economics and Business Administration, Ariel University, Ariel, \\ Israel. E-mail: eyale@ariel.ac.il
}

$\begin{array}{ll}\text { Received: July 10, } 2020 & \text { Accepted: August 10, } 2020 \quad \text { Online Published: August 17, } 2020 \\ \text { doi:10.5539/jel.v9n5p38 } & \text { URL: https://doi.org/10.5539/jel.v9n5p38 }\end{array}$

\begin{abstract}
The current study is an exploratory study designed to examine the traits that are considered essential or important for research students, from the perspective of student advisors. The study addresses the broad question of whether and how academic faculty members select research students when seeking to maximize their own research outputs and achieving their own research goals.
\end{abstract}

We employ a mixedmethods design, which incorporates content analysis based on Natural Language Processing techniques, and Structural Equation Modeling (SEM) to assess our model's goodness of fit.

Prominent traits that faculty members used to assess research candidates are investigated and discussed.

Keywords: research, advanced degrees, students, academia

\section{Introduction and Background}

Access to undergraduate education has been a key issue on the agenda of higher education systems in recent decades. For centuries, universities have preserved their elitist status, maintaining social inequities. This situation changed after WWII, when admission to higher education institutions assumed a more open, democratic character. This development occurred in most western countries over the course of the twentieth century and led to the massification of bachelor degrees. In less than 50 years, the number of awarded undergraduate degrees doubled and tripled. Israel joined the international revolution in higher education, and the effects of this global trend influenced it as well. Within two decades, the number of students in Israel increased enormously: from annual growth of $23 \%$ in the 1990 s to over $50 \%$ in 2013 . Undergraduate degrees effectively became a "degree for the masses" (Davidovitch \& Sinuany-Stern, 2016).

In the past decade in Israel, government research budgets have doubled and access to higher education has expanded, which have strengthened academic research. According to CHE data (n.d.), the higher education system in Israel has experienced a general expansion. From 21 academic institutions and 88,500 students (including 13,000 students enrolled in the Open University) in 1989/1990, the system grew to 63 institutions that awarded academic degrees and 314,400 students (including 46,200 students in the Open University) in 2015/2016, reflecting average annual growth of 5.0\%, which stemmed mainly from the establishment of academic colleges in the 1990s and the 2000s (Guri-Rosenblit, 2000). According to CHE data, Israel has the second highest percentage of the population between ages 25 and 64 with post-secondary and academic education.

State policy to increase access to higher education has important implications for graduate and doctoral studies. In $2015 / 2016$, the number of graduate students increased by $3.6 \%$ from the previous year, mainly as a result of the increase in the number of graduate students in academic colleges and academic teachers colleges $(11.2 \%$ and $14.1 \%$, respectively), while the number of graduate students in universities reflected a $0.2 \%$ decline. Indeed, in 2009/2010, graduate students constituted 19.4\% of all students, and within six years, this figure increased to $21.7 \%$. During this period, the share of undergraduate students declined from $75.8 \%$ to $73.6 \%$. In this same six-year period, the share of graduate students in academic colleges increased by $58 \%$. 
Also, in the past decade, research budgets have seen an unprecedented increase, mainly due to the policy of the CHE's Planning and Budget Committee and its view of the essential role of in maintaining Israel's international status. The increased budgets increased the number and scope of research grants available to researchers, with the aim of improving research quality. In this decade, the CHE's budget for research funds almost tripled, the budget of the National Science Foundation doubled, and the budget for the European R\&D program more than tripled. The vast majority $(80 \%)$ of competitive research grants in this decade were awarded by the National Foundation of Science and the European R\&D program. Approximately $40 \%$ of these grants were awarded in the field of medicine and life sciences, but the most significant increase occurred in the fields of engineering, mathematics, and computer sciences (grants increased by $250 \%$ over the decade). Scholarships awarded to doctoral students also increased.

In this paper we discuss one of the academic implications of Israel's social policy to extend access to higher education, focusing on academic advising of graduate students. Specifically, we explore the criteria that faculty members use to select the students they advise in order to maximize their own research outcomes and achieve their research goals.

\subsection{Competition over Student Advisors and over Advisees}

The binary system of higher education in Israel, which is sharply divided into colleges and universities, created new opportunities for students who, in the absence of the higher education reform, would not have pursued an academic education. This is also the case with respect to students who pursue graduate and advanced degrees in both types of higher education institutions. One of the results of the growth in graduate students is growing competition over advisors in academic institutions, especially advisors specializing in high-demand fields (Yair, Gueta, \& Davidovitch, 2017).

As a result of the increased access to undergraduate programs, undergraduate degrees have become "degrees for the masses." Rather than a degree held by a small elite, today, undergraduate degrees are common. This change is the topic of numerous studies that explore its implications.

Credentialism is defined as the employers' tendency to attribute excessive weight to certificates rather than to then the qualifications themselves, which created a vicious circle that drives an increasing demand for graduate and advanced degrees in an effort to compensate for the diminishing value of undergraduate degrees. In the current state of the labor market, employers have access to workers with academic degrees that may not be necessary but such candidates are available at no extra cost. This process occurs mainly because employers believe that education "enhances" their employees and they are getting more for their money when they employ individuals with a higher academic than the job typically requires. This belief leads employers to demand undergraduate and graduate degrees of candidates. If an employer can hire a candidate with a graduate degree rather than an undergraduate degree for the same wages, they will prefer to hire more highly educated employees. Credential inflation occurs when employers prefer candidates with academic degrees over candidates without academic degrees.

Many jobs across the world require an undergraduate degree. In the absence of other information on candidates, an academic degree provides employees with an assessment of the candidate's potential or quality. It is argued that, according to the human capital theory, employers use academic credentials as a screening tool and predictor of candidates' efficiency and productivity. The problem increases when a large percentage of academic graduates are unemployed (Davidovitch \& Sinuany-Stern, 2016).

A spill-over of massification toward graduate degrees is also evident. Data indicate that graduate degrees are no longer considered a step toward an academic career. The number of students in graduate programs in Israel has tripled over time, and the increase in the number of doctoral students is even larger. This figure indicates that access to higher education also extended to advanced degrees. This new reality has implications for the future of academic research.

In the past two decades, graduate programs have undergone several changes that facilitated the increase in the number of students in these programs, including the establishment of new private colleges, and new non-research graduate programs in universities and colleges alike. These institutional changes were accompanied by curricular changes, new programs, increased flexibility in study schedules, accelerated tracks, and non-research tracks. These developments raise the question of quantity versus quality, the significance of non-research graduate degrees, and the implications of these programs for doctoral programs.

Until the 1990s, Israel's higher education system was small and elitist, but it did not remain behind in this global trend, and in 1999 approved colleges to open non-research graduate programs. The decision revolutionized 
access to graduate degrees: In 2003, app. $68 \%$ of all graduate degrees were earned in a non-research track, compared to a mere $27 \%$ in the early 1990 s. The new non-research tracks adversely affected the status of Israel's universities, which suffered a cut of NIS 1.2 billion in government funding, despite the dramatic rise in the number of undergraduate students, creating budgetary stress on the universities. The universities had no choice but to join the new trend and also open non-research graduate programs in order to attract students and to support the institutions' survival. In 2005, even the most stringent universities that traditionally privileged their research activities opened non-research graduate programs (Council for Higher Education, n.d.).

Paradoxically, just as universities began to develop non-research graduate programs, which have an applied flavor, public colleges in Israel obtained approval to open research-oriented graduate programs. This approval was a significant milestone on the colleges' development.

As expected, the percentage of undergraduate degree earners who pursue a graduate degree is highest among university graduates $(39 \%$, compared to $19 \%$ of graduates of government-funded colleges and $16 \%$ of other colleges). Part of the colleges' motivation to open graduate programs is related to the obstacles that universities often pose for colleges graduates that prefer to transfer to a university for graduate studies. In the United States, institutions solved the transfer problems by the use of admission exams. In Israel, admission exams are used in graduate programs in business administration and psychology (to varying degrees, depending on the institution and the specific track), but are not generally accepted in other fields. Rather than admission exams, several institutions require graduates of colleges to complete coursework, employing various methods that circumvent the law that requires all academic degrees to be treated equally.

In summary, access to higher education also extended to graduate degrees, creating a new reality with significant implications for the future of academic research. This new situation raises the question of whether universities are handling large quantities of graduate students at the expense of the quality of their research outputs.

The current study is an exploratory study designed to examine faculty members' perceptions about the traits they consider to be essential or important for the research work of graduate students whom they advise. We address two essential traits: students' motivation and their capacity for independent learning, and examine the associations between independent learning, motivation, and research outputs.

Many studies have focused on the association between motivation for learning and school achievements, and motivation's role as an essential element in success in work. Studies have also explored motivation for academic studies, mainly undergraduate studies (Chang et al., 2014; Michalsky \& Kremarksy, 2008).

However, we found no studies on the specific association between motivation for learning and research products, or the association between capacity for independent work and research products. We also found no studies on the association between students' capacity for independent work and students' research outcomes, although the research literature shows that capacity for independent learning is a key skill for learners in the twenty-first century.

Independent learning is based on the cognitive, behavioral, and motivational elements of learners who are actively involved in their learning process. Typical traits of independent learners include high motivation, perseverance, resourcefulness, and commitment to success in learning (McTighe \& Wiggins, 2013).

In addition, independent learning and proactively engaging with knowledge develops in learners a high capacity for reasoning, critical analysis, information processing, and deductive inference. In contrast, when the majority of the material is conveyed by someone else, learners undergo very superficial information processing and storage. Independent, active learning creates a space in which a significant interaction occurs between the learner and the material, and it is in this space that learners develop their capacity to analyze and process information and infer conclusions. These skills and abilities are increasingly required by learners in the digital and technological era, which exposes them to a flood of information through multiple, diverse channels. However, without developing a capacity for independent learning, learners are unable to gain much value from the quantities of material to which they are exposed. Genuine learning occurs when independent learning is active and employs various cognitive and behavioral abilities. Moreover, active learning is an important factor in learners' identification with the subject matter (McTighe \& Wiggins, 2013). Teachers, including academic faculty, are therefore advised to support learning spaces that facilitate independent learning, allowing students to engage in significant, meaningful learning.

Research Hypotheses

H1. Candidates' motivation positively affects candidates' independent work capabilities.

H2. Independent work capabilities positively affect research capabilities and outcomes. 
H3. Candidates' personal traits* positively affect research capabilities and outcomes.

H4. References to students positively affect references to research.

H5. Independent work capabilities mediate the relationship between candidates' motivation and research capabilities and outcomes.

* A compound index of candidates' traits was investigated using text analysis, described below.

\section{Method}

\subsection{Objectives}

The purpose of the research is to examine the traits that are considered essential or important for research students, through the perspectives of student advisors. The following analysis examines the hypotheses throught development of an empirical model, demonstrating the key characteristics.

\subsection{Sample}

The survey was distributed to the senior faculty of Ariel University who had experience in supervising students, using Google Forms. Sixty completed questionnaires were collected. Among the respondents who reported demographic data, 29 were females and 28 males. Respondents', ages ranged from 41 to 49 (28.3\%), from 50 to $60(37 \%)$, and from 61 to $85(34.8 \%)$.

Teaching students to think is not an easy task (Davidovitch \& Eckhaus, 2019b). The survey included the following four open ended questions, in order to collect maximum information:

Txt1: How do you assess your student's work? Do you have a list of criteria? Please list them.

Txt2: Please describe the ideal research student. Have you ever encountered students that match this description?

Txt3: When a student asks you to be their advisor, do you have any heuristics or rules of thumb or are there any indications that help you decide whether the student is ready for research work under your supervision?

Txt4: What do you think about advising students? Is it part of your teaching duties or part of your research duties? Please explain.

\subsection{Analysis}

We used a mixed-methods analysis that incorporates empirical and qualitative techniques. Using mixed methods allows a compliment of strengths of both methods, and improves our understanding of the responses to the research questions (Davidovitch \& Eckhaus, 2019a, 2019b; Eckhaus \& Davidovitch, 2019a).

First, we manually read the texts and identified major themes (Eckhaus \& Ben-Hador, 2018) from the first open question (Txt1), which identified major criteria for evaluating candidates. Every text was tagged for its association with one or more themes (Eckhaus \& Ben-Hador, 2018). The major themes identified were motivation (Txt1_motivation, mentioned by 21 respondents) and capability for independent work (Txt1_independent, mentioned by 11 respondents). Next, text analysis was performed, as explained below.

To test the model's goodness of fit we used Structural Equation Modeling (SEM) (Eckhaus, 2019). Model fit indices considered were CMIN/DF, CFI, TLI, RMSEA. CFI and TLI values should be $\geq .95$ (Bountress et al., 2019). The ratio CMIN/DF should be lower than 2 for a good fit (Kohls, Sauer \& Walach, 2009), and RMSEA $<.06$ (Psychogiou, Russell \& Owens, 2020).

\subsection{Text Analysis}

We employed automated content analysis techniques using TEXTIMUS software (Eckhaus \& Ben-Hador, 2019), which supports big data analysis. The first stage was to generate $\mathrm{N}$-gram combinations. These are adjacent sequences of $\mathrm{n}$ words from a given text (Davidovitch \& Eckhaus, 2020), and the procedure is widely used in Natural Language Processing (NLP) applications. The next stage included the Bag-of-Words (BoW) technique (Eckhaus \& Davidovitch, 2018a, 2018b) to explore a set of predefined words in the corpus. In this process, the keywords are assigned a value specifying the number of its occurences in each document, or if the word appears or not in a binary representation. Accordingly, we examined keyword frequencies, and divided the top frequency words, which generated the research variables, into the following groups: Advantages (desired qualities of candidates) included conscientious, enterprising, original, serious, organized, responsible, independent thinker, analytical skills, professional skills, problem solver, independent learning capacity, independent. Research included speaking of research and research capabilities, and Students. Note that Txt1_independent is a binary form of the group summed in Advantages, which was required in order to analyze the mediation with only one quality rather than the entire set. However, a correlation was entered into the model between Advantages and 
Txt1_independent. Age and Gender were also entered, as typical control variables (Davidovitch \& Eckhaus, 2019a; Eckhaus \& Davidovitch, 2019a, 2019b).

\section{Results}

The correlations, means, and standard deviations are presented in Table 1. Since Txt1_motivation and Txt1_independent are binary coded, we present Spearman correlations.

Table 1. Correlations, means, and SD

\begin{tabular}{llllll}
\hline & Txt1_motivation & Txt1_independent & Advantages & Research & Student \\
\hline Txt1_motivation & - & & & & \\
Txt1_independent & $.44^{* * *}$ & - & & & \\
Advantages & .22 & $.39^{* *}$ & - & & \\
Research & .16 & $.36^{* *}$ & $.46^{* * *}$ & - & $.36^{* *}$ \\
Student & .01 & .003 & .21 & 1.75 & 1.72 \\
Mean & .37 & .18 & 1.89 & 1.67 & 1.61 \\
SD & .49 & .39 & 2.02 & & \\
\hline
\end{tabular}

Note. ${ }^{* *} p<.01, * * * p<.001$.

The model and standardized coefficients are presented in Figure 1.

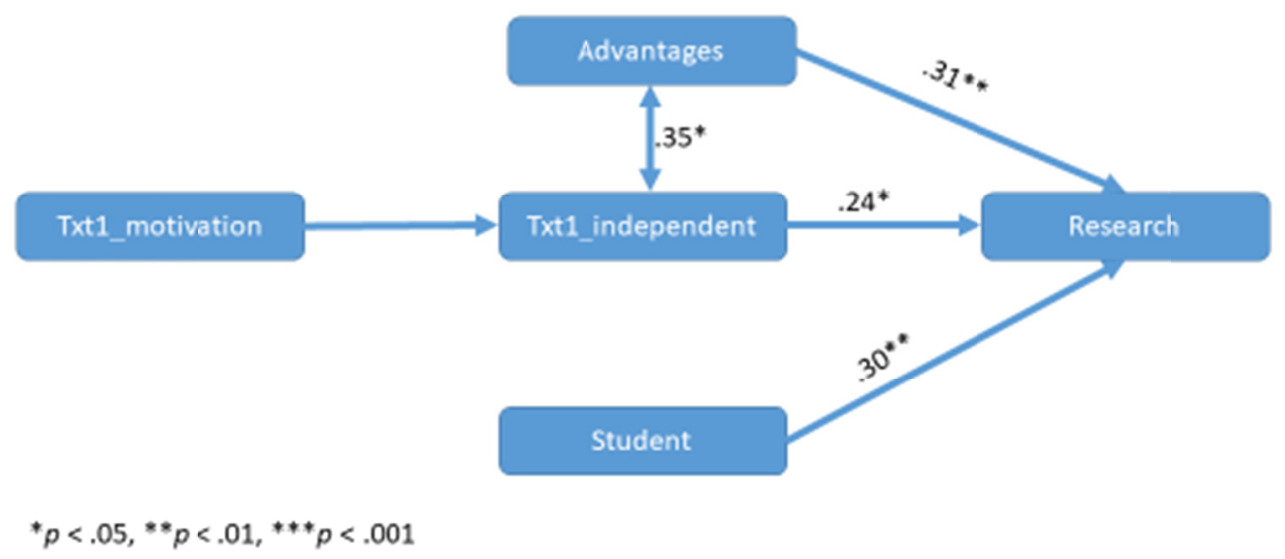

Figure 1. Model and standardized coefficients

The hypothesized model showed a good fit: $\mathrm{CMIN} / \mathrm{DF}=1.19, p>.05, \mathrm{CFI}=.98, \mathrm{TLI}=.952, \mathrm{RMSEA}=.057$. All hypotheses were supported. Txt1_motivation positively affects Txt1_independent (H1) $(\beta=.24, p<.001)$. Txt1_independent positively affects Research (H2) $(\beta=.39, p<.05)$. Advantages positively affects Research (H3) $(\beta=.31, p<.01)$. Student positively affects Research (H4) $(\beta=.30, p<.01)$.

The mediation of Txt1_independent in the relationship between Txt1_motivationi and Research (H5) was also supported. Sobel mediation test (Sobel, 1982) was significant (Sobel $z=2.30, p<.05$ ). The bootstrapped Confidence Interval (CI) for the indirect effect ranges between [0.081, 1.013] (Bootstrap sample size $=5,000$ ).

Age and gender did not have a statistical effect on either Txt1_motivation or Txt1_independent.

\section{Summary and Discussion}

We are witnessing the massification of graduate and advanced degree programs. As a result of the increased access to higher education, undergraduate degrees have become a basic level of education targeting the masses, a new substitute for matriculation certificates, while graduate degrees have become the next step in efforts to achieve social mobility.

While the research literature offers a large number of studies on student admission requirements and the predictive relationship between admission requirements (e.g., matriculation score, psychometric score, personal interview) and academic achievements, we found no studies that focus on academic advisors to graduate students. As the number of graduate students increases, and the number of faculty members with rich research experience 
in their field is limited, competition over advisors increases accordingly.

This is an exploratory study designed to examine the traits considered to be critical or important in research students, from the perspective of the academic advisors who supervise their research work. Using natural language processing, we analyzed traits considered to be advantageous for graduate research candidates, and the association of these traits with research capabilities and outputs. Findings of the current study point to two prominent traits that faculty members use to assess graduate students: their capacity for independent work and their motivation for research. Findings also indicate that the capacity for independent work mediates between graduate students' motivation and their ability to generate research outputs. Findings raise the question of how faculty members select their potential research students in order to maximize research outputs and attain their own research targets. Research advisors are experienced faculty members who are motivated to contribute to the training of a new generation of researchers and support them in producing research achievements, and therefore the traits they seek, which extend beyond numerical scores, speak to candidates' abilities, specifically their ability to work independently and their motivation. These two traits may predict the success of both graduate students and their advisors in the lengthy and demanding research program.

\section{References}

Bountress, K. E., Cohen, J. R., Ruggiero, K., Davidson, T., Calhoun, C. D., Nelson, F., ... Gilmore, A. K. (2019). Offspring self-disclosure predicts substance-related outcomes in an emergency department sample of young adults with traumatic injury. Journal of Substance Use, 25(3), 313-317. https://doi.org/10.1080/14659891.2019.1692925

Chang, C.-S., Liu, E. Z.-F., Sung, H.-Y., Lin, C.-H., Chen, N.-S., \& Cheng, S.-S. (2014). Effects of online college student's Internet self-efficacy on learning motivation and performance. Innovations in Education and Teaching International, 51(4), 366-377. https://doi.org/10.1080/14703297.2013.771429

Council for Higher Education. (n.d.). The higher education system 2009-2010: A decade of academic excellence: Doubled budgets, access, and reinforcement of research. Retrieved from https://che.org.il/wp-content/uploads/2019/10/טט-נתונים-לקראת-פתיחת-שנת-הלימודים-האקדמית-תשפ.pdf

Davidovitch, N., \& Eckhaus, E. (2019a). Student evaluation of lecturers - what do faculty members think about the damage caused by teaching surveys? Higher Education Studies, 9(3), 12-21. https://doi.org/10.5539/hes.v9n3p12

Davidovitch, N., \& Eckhaus, E. (2019b). Teaching students to think - faculty recommendations for teaching evaluations employing automated content analysis. International Journal of Higher Education, 8(3), 83-93. https://doi.org/10.5430/ijhe.v8n3p83

Davidovitch, N., \& Eckhaus, E. (2020). Senior faculty opinions on the significance of retirement age-Employing natural language processing. Higher Education Studies, 10(2), 38-44. https://doi.org/10.5539/hes.v10n2p38

Davidovitch, N., \& Sinuany-Stern, Z. (2016). On research, teaching, and gender: A case study on assessing research and teaching performance in Israel's higher education system. Paper presented at the First National Conference of Gender Programs in Israel, Bar Ilan University, Israel. https://doi.org/10.4236/ce.2016.711164

Eckhaus, E. (2019). How to be happy. Blog section on www.artistila.com. Retrieved from http://www.artistila.com/how-to-by-happy/

Eckhaus, E., \& Ben-Hador, B. (2018). To gossip or not to gossip: Reactions to a perceived request to gossip-a qualitative study. Trames: A Journal of the Humanities and Social Sciences, 22(3), 273-288. https://doi.org/10.3176/tr.2018.3.04

Eckhaus, E., \& Ben-Hador, B. (2019). Gossip and gender differences: a content analysis approach. Journal of Gender Studies, 28(1), 97-108. https://doi.org/10.1080/09589236.2017.1411789

Eckhaus, E., \& Davidovitch, N. (2018a). Impact of gender and conference size on conference preferences-employing natural language processing. International Journal of Educational Methodology, 4(1), 45-52. https://doi.org/10.12973/ijem.4.1.45

Eckhaus, E., \& Davidovitch, N. (2018b). Improving academic conferences—criticism and suggestions utilizing natural language processing. European Journal of Educational Research, 7(3), 445-450. https://doi.org/10.12973/eu-jer.7.3.445 
Eckhaus, E., \& Davidovitch, N. (2019a). How do academic faculty members perceive the effect of teaching surveys completed by students on appointment and promotion processes at academic institutions? A case study. International Journal of Higher Education, 8(1), 171-180. https://doi.org/10.5430/ijhe.v8n1p171

Eckhaus, E., \& Davidovitch, N. (2019b). Potential for blocking advancement: teaching surveys for student evaluation of lecturers. International Journal of Educational Methodology, 5(3), 401-406. https://doi.org/10.12973/ijem.5.3.401

Guri-Rosenblit. (2000). Accessibility to higher education: Social aspects and selection processes. In S. Guri-Rosenblit (Ed.), Position papers. Jerusalem: Van Leer Institute.

Kohls, N., Sauer, S., \& Walach, H. (2009). Facets of mindfulness-Results of an online study investigating the Freiburg mindfulness inventory. Personality and Individual Differences, 46(2), 224-230. https://doi.org/10.1016/j.paid.2008.10.009

McTighe, J., \& Wiggins, G. P. (2013). Essential questions: Opening doors to student understanding. Alexandria, VA: ASCD.

Michalsky, T., \& Kremarksy, B. (2008). Developing self-direction in learning among student teachers in an online setting in connection with learning and teaching perceptions. Megamot, 45(4), 765-798.

Psychogiou, L., Russell, G., \& Owens, M. (2020). Parents' postnatal depressive symptoms and their children's academic attainment at 16 years: pathways of risk transmission. British Journal of Psychology, 111(1), 1-16. https://doi.org/10.1111/bjop.12378

Yair, G., Gueta, N., \& Davidovitch, N. (2017). The law of limited excellence: Publication productivity of Israel prize laureates in the life and exact sciences. Scientometrics, 113(1), 299-311 https://doi.org/10.1007/s11192-017-2465-0

\section{Copyrights}

Copyright for this article is retained by the author, with first publication rights granted to the journal.

This is an open-access article distributed under the terms and conditions of the Creative Commons Attribution license (http://creativecommons.org/licenses/by/4.0/). 